Article

\title{
Linear and Nonlinear Causality between Energy Consumption and Economic Growth: The Case of Mexico 1965-2014
}

\author{
Mario Gómez ${ }^{1, *}$, Aitor Ciarreta ${ }^{2}$ and Ainhoa Zarraga ${ }^{3}$ iD \\ 1 Instituto de Investigaciones Económicas y Empresariales (Economic and Business Research Institute), \\ Universidad Michoacana de San Nicolás de Hidalgo, Edificio ININEE, Ciudad University, C.P. 58030, \\ Morelia, Mich., Mexico \\ 2 Department of Economic Analysis II, University of the Basque Country (UPV/EHU), \\ Avda. Lehendakari Aguirre, 83, 48015 Bilbao, Spain; aitor.ciarreta@ehu.eus \\ 3 Department of Applied Economics III (Econometrics and Statistics), \\ University of the Basque Country (UPV/EHU), Avda. Lehendakari Aguirre, 83, 48015 Bilbao, Spain; \\ ainhoa.zarraga@ehu.eus \\ * Correspondence: mgomez@umich.mx; Tel.: +52-(443)-316-5131
}

Received: 12 February 2018; Accepted: 13 March 2018; Published: 29 March 2018

\begin{abstract}
This paper analyzes the causal link between aggregated and disaggregated levels of energy consumption and economic growth in Mexico between 1965 and 2014, with the presence of structural breaks stemming from the series. To that end, unit root with structural breaks, cointegration, and linear and nonlinear causality tests are employed. The results show that there is a long-run relationship between production, capital, labor, and energy, and linear causal links from total and disaggregated energy consumption to economic growth. A nonlinear causality also exists from energy consumption, the transport sector, capital, and labor to output. These results support the growth hypothesis, which maintains that energy is an important input factor for economic activity and that energy conservation policies impact the economic growth in Mexico.
\end{abstract}

Keywords: causality; economic growth; structural breaks; energy consumption; Mexico

\section{Introduction}

The causal link between energy consumption and economic growth has been examined in the literature ever since the seminal study by Kraft and Kraft [1] was published. Four hypotheses have been derived from the analysis of the dynamic relationships between economic growth and energy consumption: the growth hypothesis, i.e., energy consumption causes economic growth, so any energy conservation policies could adversely affect economic growth; the conservation hypothesis, i.e., economic growth causes energy consumption, and energy conservation policies have therefore little or no impact on growth; the neutrality hypothesis, i.e., there is no causal link between the variables, which implies that energy conservation policies do not affect economic growth; and the feedback hypothesis, i.e., two-way causality exists, whereby there is interdependence and complementarity between the two variables. In this regard, [2] shows that $27.87 \%$ of studies support the conservation hypothesis, $22.95 \%$ support the growth hypothesis, $31.15 \%$ support the neutrality hypothesis, and $18.03 \%$ support the feedback hypothesis. The lack of consensus is probably due to the differences in the characteristics among countries, the data sets used, the variables included in the analysis, and the econometric methodology used.

The gradual opening up of the world economy after World War II, infrastructure development, and technological advances in transport and equipment have helped to explain the increase in demand 
for energy in all forms, leading to other major challenges, such as its impact on the environment, sustainability, supply capacity, and finding alternative energy sources [3]. This issue is currently very important, as an estimated 6.1 million people annually die from air pollution, which is mainly caused by the production and use of energy by human activities (e.g., power plants, industry, households, transport, and agriculture), and results in negative effects on human health, the acidification and eutrophication of water and soil, crop damage, and climate change [4]. Despite the greater focus on this issue and the corresponding effort to lower environmental damage, fossil fuels (i.e., oil, coal, and natural gas) still dominate in global energy consumption. These fossil fuels had an $81 \%$ share in the last 25 years. That ratio did not change between 1989 and 2014, although the use of oil dropped, from $37 \%$ to $31 \%$; over that same period, the use of natural gas rose from $19 \%$ to $21 \%$ and coal increased from $25 \%$ to $28 \%$ [4].

Some studies [5-17] focus on total energy consumption whereas [18-22] disaggregate per type of energy source or per consumption sector. The latter seek to better understand the relative importance of each sector or type of energy source in economic growth. Another part of the literature includes energy as a factor in the production function, in addition to capital and labor, in order to establish the influence of energy on the economy and to better design the energy policies of the countries [23-25]. More recently, the literature has focused on analyzing economic growth and energy consumption by type of transport, because this sector is one of the most dynamic and plays a very important role for economic and social development [26,27].

Some economic events, such as changes in economic conditions, changes in energy policy, and fluctuations in the price of energy, can cause structural changes in energy consumption behavior; it is imperative to incorporate them to avoid the possibility of model misspecification affecting statistical inference $[9,28]$. Due to the presence of such structural changes in the variables, the nonlinear context may be more appropriate for investigating the relationship between energy consumption and economic growth $[11,28]$.

In the mid-eighties, the Mexican economy, like that of many other Latin American countries, began to implement structural reforms, after four decades employing an import-substitution model, which was obviously exhausted. This entailed opening its market up to competition and foreign investment, privatizing public enterprises, deregulating the domestic market, and finally, signing the North American Free Trade Agreement (NAFTA) in 1992, all aimed at increasing economic efficiency (the agreement came into force in 1 January 1994). Alongside these reforms, there were strong devaluations and economic crises in 1976, 1982, 1987, and 1994-1995. These events in the Mexican economy might imply structural changes that should be incorporated into economic modeling.

The energy sector has played an important role in the economic and social growth and the development of Mexico. Between 2000 and 2011, energy consumption grew at an average annual rate of $2.08 \%$, while GDP increased at $1.82 \%$ and primary energy production decreased at a rate of $0.3 \%$ [29]. These trends indicate that Mexico will face a major energy deficit by 2020. It is important to note that Mexico has currently set targets for environmental issues, such as reducing greenhouse gas emissions by $30 \%$ by 2020 compared to the baseline figure [29]. However, this goal does not appear to be compatible with the energy reform approved on December 20,2013, and the first package of secondary legislation published on 11 August 2014 [29], as they focus on the participation of non-renewable resources in the country's energy sector and not on either their environmental impact or the promotion of renewable energies in the national energy sector. This is worrying for the country in a global context, as energy consumption is increasing and total fossil fuel reserves are becoming depleted and neglected. In Mexico, air pollution is a significant problem both in urban and rural areas. Dependence on biomass for cooking and other energy uses falls outside the usual patterns among Organization for Economic Co-operation and Development (OECD) member countries. Although a $30 \%$ increase in energy demand is expected in 2040, the projections do not show a proportional increase in emissions of air pollutants in Mexico. However, the impact of air pollution on health persists; the number of 
premature deaths attributable to air pollution is expected to increase from 12,500 cases per year at present to 15,500 in 2040 [4].

Some studies have already attempted to determine the relationship between energy and economic growth in Mexico. Reference [30] finds no causal link; reference [31] finds a bidirectional causality between energy consumption and product changes from 1965 to 2001; [32] finds temporal causality running from economic growth to energy consumption and finally, [33] finds support for the neutrality hypothesis.

This research seeks to analyze the dynamic relationships between production and energy consumption in Mexico between 1965 and 2014. Our paper differs from these studies on several points: (1) A model with four variables (energy consumption, economic growth, capital, and labor) is estimated to avoid the problem of the omitted variable in a bivariate system; (2) the newly developed Residual Augmented Least Squares-Lagrange Multiplier (RALS-LM) unit root test with trend-breaks [34] and the co-integration test proposed by [35] are employed; (3) in addition to the linear Granger causality, a nonlinear causal analysis proposed by [36] is used; (4) the analysis is conducted for both aggregated and disaggregated energy consumption.

The results of causality help to device the importance of energy consumption as an input for economic growth in Mexico. In this way, we seek to propose policies oriented towards sustainable economic growth and efficient use of energy resources in Mexico.

The rest of the paper is structured as follows: Section 2 describes the econometric methodology. Section 3 presents the data and period studied. In Section 4, the empirical results are presented and analyzed, and finally, the conclusions are discussed in Section 5.

\section{Methodology}

Our research assumes the context of a production function, where energy consumption is considered a separate input from capital and labor, as discussed in [7,37]. The general form of the production function is:

$$
G D P_{t}=f\left(E C_{t}, K_{t}, L_{t}\right)
$$

where real output (GDP) at time $t$ is a function of energy consumption (EC), labor (L), and capital (K). We assume that these inputs are weakly separable from other inputs such as materials and services. Equation (1) is parameterized as a Cobb-Douglas production function and, taking natural logarithms on both sides of the equation, can be expressed as follows:

$$
\ln G D P_{t}=\alpha+\beta \ln E C_{t}+\gamma \ln K_{t}+\delta \ln L_{t}+u_{t}
$$

where $u_{t}$ is the error term.

First, the order of integration of the series is determined using the Augmented Dickey-Fuller (ADF) [38] and Phillips-Perron (PP) [39] unit root tests. As these tests are well known in the literature, they are not described in this paper. The Lagrange Multiplier (LM) tests developed by [40,41] and the RALS-LM test developed by [34] for one and two structural breaks, respectively, are used to take the possible presence of structural changes into account.

Reference [40] consider the following data generation process (DGP):

$$
y_{t}=\delta^{\prime} Z_{t}+e_{t} \text { with } e_{t}=\beta e_{t-1}+\varepsilon_{t}
$$

where $y_{t}$ is the series of interest to be analyzed, i.e., GDP and all the input variables of the production function, $Z_{t}$ is a vector of exogenous variables and $\varepsilon_{t}$ is iid $N\left(0, \sigma^{2}\right)$. With two structural changes, the Model A allows two structural changes in the intercept and the Model $C$ allows two structural changes in the level and slope. In Model A, $Z_{t}=\left[1, t, D_{1 t}, D_{2 t}\right]^{\prime}$ where $D_{j t}=1$ for any $t \geq T_{b j}+1, j=1,2$, and 0 otherwise, $T_{B j}$ is the time period of structural change. In Model $C, Z_{t}=\left[1, t, D_{1 t}, D_{2 t}, D T_{1 t}, D T_{2 t}\right]^{\prime}$, where $D_{j t}=1$ for $t \geq T_{B j}+1, j=1,2$ and 0 otherwise. 
The DGP incorporates structural changes under the null hypothesis of unit root and the alternative of trend stationarity, and are determined endogenously, based on the data. The test statistic is obtained from the following regression:

$$
\Delta y_{t}=\delta^{\prime} \Delta Z_{t}+\phi \widetilde{S}_{t-1}+u_{t}
$$

where $\widetilde{S}_{t}=y_{t}-\widetilde{\varphi}_{x}-Z_{t} \widetilde{\delta} ; t=2, \ldots, T ; \widetilde{\delta}$ are the regression coefficients of $\Delta y_{t}$ on $\Delta Z_{t}$; and $\varphi_{x}$ is given by $y_{1}-Z_{1} \widetilde{\delta} \cdot y_{1}$ and $Z_{1}$ represent the first observation of $y_{t}$ and $Z_{t}$, respectively. The LM unit root test statistic, $\tau_{L M}$, is the $t$-statistic for the hypothesis $\phi=0 \tau_{\mathrm{LM}}$.

As explained in $[34,42,43]$, when there are trend breaks, the LM statistic, $\tau_{L M}$, depends on the location parameter, $\lambda_{i}$, which indicates the fraction of the subsamples in each regime, such that $\lambda_{1}=T_{B 1} / T$ and $\lambda_{2}=\left(T_{B 2}-T_{B 1}\right) / T$. Reference [42] suggests a simple transformation, which can make the unit root test statistic free of the dependency on the break location. To that end, $\widetilde{S}_{t}$ is replaced by $\widetilde{S}_{t}^{*}$ in Equation (4), with $\widetilde{S}_{t}^{*}=\left(\frac{T}{T_{B 1}}\right) \widetilde{S}_{t}$ for $t \leq T_{B 1}$ and $\widetilde{S}_{t}^{*}=\left(\frac{T}{T_{B 2}-T_{B 1}}\right) \widetilde{S}_{t}$ for $T_{B 1}<t \leq T_{B 2}$. The resulting equation is:

$$
\Delta y_{t}=\delta^{\prime} \Delta Z_{t}+\phi \widetilde{S}_{t}^{*}+\sum_{j=1}^{k} d_{j} \Delta \widetilde{S}_{t-j}+e_{t}
$$

where $\Delta \widetilde{S}_{t-j}$ and $j=1, \ldots, k$. These terms are included to correct error autocorrelation. The $t$-statistic for $\phi=0$ is indicated by $\widetilde{\tau}_{L M}^{*}$, whose distribution is invariant to $\lambda_{i}$. In order to improve the power of the LM test, [34] adopts a procedure to employ the information of non-normal errors, and they suggest modifying the testing regression (5) as follows:

$$
\Delta y_{t}=\delta^{\prime} \Delta Z_{t}+\phi \widetilde{S}_{t}^{*}+\sum_{j=1}^{p} d_{j} \triangle \widetilde{S}_{t-j}+\hat{w}_{t}^{\prime} \gamma+u_{t}
$$

where $\hat{w}_{t}$ captures the moment conditions, employing the second and third moments of the residuals of the regression (6). Letting $\hat{m}_{j}=T^{-1} \sum_{t=1}^{T} \hat{e}_{t}^{j}$, the augmented term could be given as:

$$
\hat{w}_{t}=\left[\hat{e}_{t}^{2}-\hat{m}_{2}, \hat{e}_{t}^{3}-\hat{m}_{3}-3 \hat{m}_{2} \hat{e}_{t}\right] \text {, }
$$

where the moment conditions, $\mathrm{E}\left[\hat{w}_{t}\right]=0$, reveal the redundancy condition, that knowledge of higher moments $m_{j+1}$ are uninformative if $m_{j+1}=j \sigma^{2} m_{j-1}$. This condition is satisfied only with the normal distribution. Under non normality, the efficiency of the estimators is enhanced by adding the augmented term, $\hat{w}_{t}$, and therefore, the power of the test is increased. The corresponding $\mathrm{t}$-statistic for $\phi=0$ is $\tau_{R A L S-L M}^{*}$, and the asymptotic distribution is given as $\tau_{R A L S-L M}^{*} \rightarrow \rho \tau_{L M}^{*}+\sqrt{1-\rho^{2}} Z$, where $\rho$ indicates the relative ratio of the variances of two error terms, $\rho^{2}=\mathrm{E}\left(u_{t}^{2}\right) / E\left(e_{t}^{2}\right)$.

We use the autoregressive distributed lag (ARDL) bounds testing approach proposed by [35] to test for cointegration or a long-run relationship between the variables. This method enables the testing of cointegration, regardless of whether the regressors are $\mathrm{I}(0), \mathrm{I}(1)$, or mutually cointegrated. It provides two critical sets of values: one that is appropriate when all regressors are $\mathrm{I}(0)$ and another that is appropriate when all regressors are I(1). It is important to note that these critical values are not valid for variables with an integrated process of order two, I(2). The test involves estimating the following unrestricted error correction model (ECM) in differences, considering each variable in turn as the dependent variable:

$$
\begin{gathered}
\Delta G D P_{t}=\alpha_{1}+\sum_{i=1}^{m} \alpha_{2 i} \Delta G D P_{t-i}+\sum_{i=1}^{m} \alpha_{3 i} \Delta K_{t-i}+\sum_{i=1}^{m} \alpha_{4 i} \Delta L_{t-i}+\sum_{i=1}^{m} \alpha_{5 i} \Delta E C_{t-i} \\
+\beta_{1} G D P_{t-1}+\beta_{2} K_{t-1}+\beta_{3} L_{t-1}+\beta_{4} E C_{t-1}+e_{t}
\end{gathered}
$$

where $\Delta$ indicates the first difference, $e_{t}$ is the error term, and $m$ is selected according to the AIC criterion. The procedure is based on the null hypothesis of no cointegration, $H_{0}: \beta_{s}=0$, against the alternative, $H_{1}: \beta_{s} \neq 0, s=1, \ldots, 4$. The null hypothesis is rejected if the value of the $\mathrm{F}$ statistic is above the critical values, and it is accepted if it is below them. However, knowledge of the integration order 
of the series is required if the F statistic falls between the upper and lower critical values. Reference [44] proposes critical values for data sets between 30 and 80 observations; these are used in this research.

Linear causality is then tested, using the $[45,46]$ tests. The former states that causality exists when lagged values of a variable, say $Y$, have explanatory power on another variable $X$. If that is the case, lagged values of $Y$ can help to reduce the prediction error of current $X$. In order to test for linear Granger causality between two series, a conventional $F$ statistic is applied in vector autoregression (VAR) models. However, this methodology requires the series being stationary since using non-stationary data can yield spurious causality results. Reference [47] argues that, if the variables are co-integrated, an ECM must be estimated instead of a VAR in testing Granger causality. In this case, the first step would be to estimate the long-term model in Equation (2), and the second step would be to estimate an ECM that includes the variables in first differences and the error correction term lagged one period (ECT-1).

Some traditional unit root tests might have low power when the sample period is small and the causality results could be affected. To overcome this problem we follow [46] who propose an alternative approach for testing causality in a VAR model, regardless of the order of integration of the series and of whether or not they are co-integrated. The procedure uses the modified Wald test statistic for restricting the parameters in the VAR (k), where $k$ is the order of the lags in the system. The statistic has an asymptotic chi-square distribution when the VAR $(k+d m a x)$ is estimated (where dmax is the maximum expected order of integration of the variables in the system).

Regarding nonlinear causality, [48] proposes a nonparametric test in a bivariate system, based on the idea that once linear causality is captured by the linear system, any remaining improvement in the predictive power of one residual series for another can be considered nonlinear. In this paper, the generalization of the test for the multivariate setting proposed by [36] is used to test the null hypothesis that a vector series $Y_{t}$ does not strictly Granger cause another vector series $X_{t}$.

\section{Data}

Annual data on output and capital are obtained from the [49]. Output is measured by real GDP (in constant 2005 US dollars). In line with some previous studies [50,51], the gross fixed capital formation is used as a proxy variable (in constant 2005 US dollars) in the absence of capital stock. The labor variable is taken from [52] and is measured using the number of people employed (in thousands). Data on EC and the disaggregation into energy consumption from the transport sector (ECTR), the industrial sector (ECI), the residential sector (ECR), and the agriculture sector (ECA) are measured in petajoules; the data are obtained from the [29]. The sample period runs from 1965 to 2014. Figure 1 plots GDP, K, L, and EC, expressed in natural logarithms. GDP, EC, and K have a positive trend, with strong, sudden movements in the early eighties (1982-1983), the mid-nineties (1994-1995), and around 2009, which could indicate structural changes in the time series. L exhibits a relatively stable behavior in relation to the other variables. 

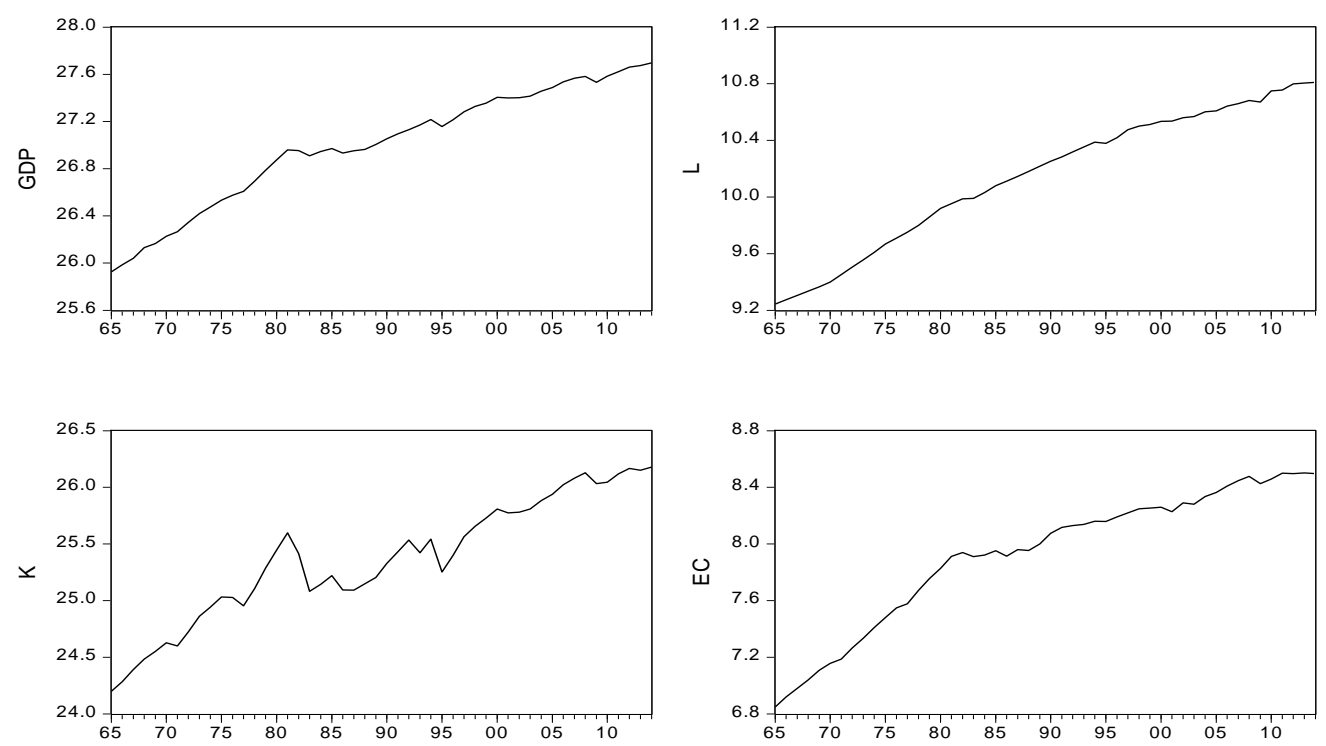

Figure 1. GDP, K, L, and EC. Sources: World Bank [49], Secretary of Energy [29], and The Conference Board Total Economy Database [52].

Figure 2 plots the energy consumption by sector. A positive trend can be seen, with some sharp movements in the early eighties, mid-nineties, and around 2009. These sudden movements in variables could be explained by the economic and financial crises in 1976, 1982, and 1994. The common elements are: (1) a non-controllable external deficit; (2) an overvalued currency; (3) a major currency flight; and (4) policy measures implemented by the Mexican government that followed the lines of the adjustment programs of the International Monetary Fund [53]. The sudden movements around 2009 could be explained by the impact of the global financial crisis.

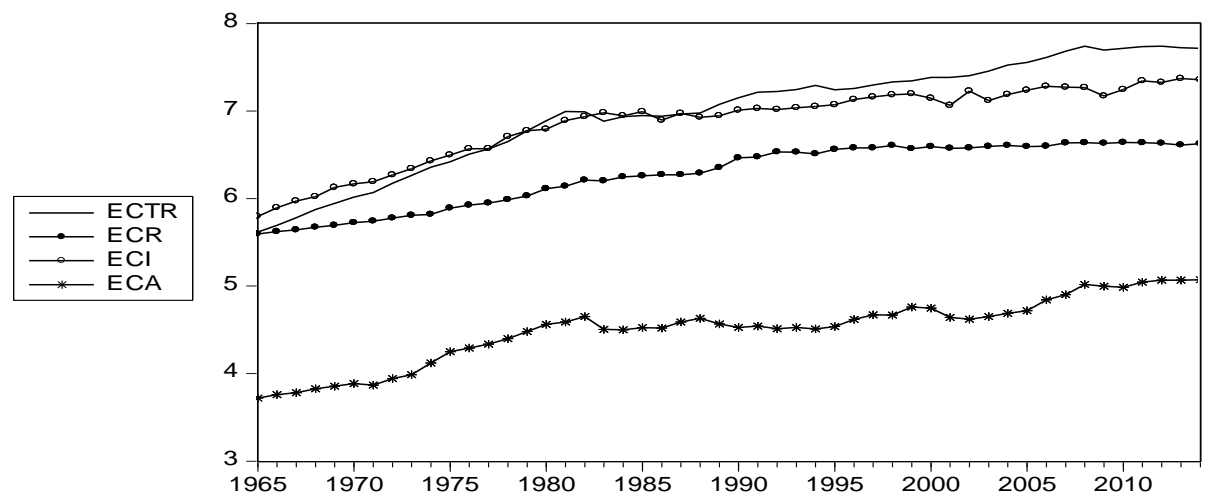

Figure 2. Energy consumption by sectors: the industrial sector (ECI), the transport sector (ECTR), the residential sector (ECR), and the agriculture sector (ECA). Source: Secretary of Energy [24].

Table 1 presents the correlation coefficients between energy consumption and GDP for Mexico. These results show high levels of correlation at both the aggregated and disaggregated levels, which means a high degree of linear relation between variables and does not necessarily imply causality. 
Table 1. Correlation matrix: Energy consumption and economic growth in Mexico.

\begin{tabular}{ccccccc}
\hline Variables & GDP & EC & ECTR & ECR & ECI & ECA \\
\hline GDP & 1 & - & - & - & - & - \\
EC & 0.995 & 1 & - & - & - & - \\
ECTR & 0.996 & 0.998 & 1 & - & - & - \\
ECR & 0.975 & 0.981 & 0.976 & 1 & - & - \\
ECI & 0.979 & 0.992 & 0.985 & 0.965 & 1 & - \\
ECA & 0.967 & 0.969 & 0.971 & 0.917 & 0.964 & 1 \\
\hline
\end{tabular}

Source: Own calculations based on the sample. The abbreviations in Table 1 are: real output (GDP), energy consumption (EC), and the disaggregation of energy consumption into transport sector (ECTR), industrial sector $(\mathrm{ECI})$, residential sector (ECR), and agriculture sector (ECA).

\section{Results}

We begin by analyzing the order of integration of the time series. In Appendix A, the Table A1 shows the results of the ADF and PP unit root tests. The unit root null hypothesis cannot be rejected for all the variables in levels, but they are stationary in first differences at the $1 \%$ significance level. However, structural breaks could be present; if they are not taken into account in the econometric modeling, erroneous results may be generated. To that end, the LM and RALS-LM tests for one and two structural breaks are performed, respectively, as defined by $[34,40,41]$. The results of the tests for one structural break are reported in Table 2.

The results of the LM test show evidence of stationarity for the variables K, EC, ECTR, and ECI at the $5 \%$ significance level or better. The null hypothesis is rejected when the RALS-LM test is applied for the variables GDP, K, L, EC, and ECI at the $10 \%$ level or better. The rest of the variables are integrated of order one.

The unit root test results for two structural breaks are reported in Table 3. As observed, when the LM statistic is applied, all the variables are stationary at the $5 \%$ significance level or better, except GDP, which is stationary at the $10 \%$ level, and L and ECA, which are integrated of order one. By contrast, all variables are stationary when the RALS-LM test is applied. Thus, stationarity of energy consumption has important policy implications for energy conservation, because a shock will affect energy consumption only temporarily; it will return to its growth path in the long term.

Table 2. LM and RALS-LM unit root tests with one structural break.

\begin{tabular}{ccccccccc}
\hline Variable & Model & $\begin{array}{c}\text { Structural } \\
\text { Break }\end{array}$ & $\begin{array}{c}\text { LM } \\
\text { Statistic }\end{array}$ & $\begin{array}{c}\text { Lag } \\
\text { Length }\end{array}$ & $\begin{array}{c}\text { Structural } \\
\text { Break }\end{array}$ & RALS-LM & $\hat{\rho}^{2}$ & $\begin{array}{c}\text { Lag } \\
\text { Length }\end{array}$ \\
\hline GDP & Model C & 1984 & -3.57 & 1 & 1983 & $-3.70^{* *}$ & 0.99 & 0 \\
K & Model C & 1985 & $-4.57^{* *}$ & 2 & 1982 & $-4.73^{*}$ & 0.91 & 2 \\
L & Model C & 1991 & -3.26 & 0 & 1992 & $-3.02^{* * *}$ & 0.56 & 1 \\
EC & Model C & 1978 & $-4.72^{* *}$ & 2 & 1982 & $-6.91^{*}$ & 0.98 & 0 \\
ECR & Model C & 1992 & -3.83 & 2 & 1997 & -1.95 & 0.81 & 2 \\
ECTR & Model C & 1977 & $-5.18^{*}$ & 4 & 1980 & -2.38 & 0.81 & 0 \\
ECI & Model C & 1981 & $-5.57^{*}$ & 0 & 1982 & $-6.91^{*}$ & 0.65 & 0 \\
ECA & Model C & 1985 & -2.81 & 1 & 1981 & -2.39 & 0.91 & 1 \\
First differences & & & & & & & & \\
$\Delta$ GDP & Model A & 1982 & $-6.63^{*}$ & 0 & 1982 & $-7.44^{*}$ & 0.63 & 0 \\
$\Delta$ KK & Model A & 1982 & $-6.78^{*}$ & 0 & 1982 & $-8.30^{*}$ & 0.58 & 0 \\
$\Delta$ L & Model A & 2007 & $-8.25^{*}$ & 0 & 1971 & $-6.69 *$ & 0.80 & 0 \\
$\Delta$ EC & Model A & 1982 & $-7.00^{*}$ & 0 & 1982 & $-6.52^{*}$ & 0.98 & 0 \\
$\Delta$ ECR & Model A & 1992 & $-7.17^{*}$ & 0 & 1991 & $-8.45^{*}$ & 0.78 & 0 \\
$\Delta$ ECTR & Model A & 1982 & $-5.09^{*}$ & 0 & 1982 & $-4.97^{*}$ & 0.90 & 0 \\
$\Delta$ ECI & Model A & 2010 & $-9.07^{*}$ & 0 & 1987 & $-9.39^{*}$ & 0.80 & 0 \\
$\Delta$ ECA & Model A & 1980 & $-5.76^{*}$ & 0 & 1982 & $-4.23^{*}$ & 0.85 & 0 \\
\hline
\end{tabular}

Note: ${ }^{*}, * *$, and ${ }^{* * *}$ denote rejection of the null hypothesis at the $1 \%, 5 \%$, and $10 \%$ levels, respectively. The abbreviations are: real output (GDP), energy consumption (EC), labor (L), capital (K), and the disaggregation of energy consumption into transport sector (ECTR), industrial sector (ECI), residential sector (ECR), and agriculture sector (ECA). The critical values for the LM and RALS-LM tests are obtained from [34,40], respectively. 
Table 3. Unit root tests with two structural breaks.

\begin{tabular}{ccccccccc}
\hline Variable & Model & $\begin{array}{c}\text { Structural } \\
\text { Breaks }\end{array}$ & $\begin{array}{c}\text { LM } \\
\text { Statistic }\end{array}$ & $\begin{array}{c}\text { Lag } \\
\text { Length }\end{array}$ & $\begin{array}{c}\text { Structural } \\
\text { Break }\end{array}$ & RALS-LM & $\hat{\rho}^{2}$ & $\begin{array}{c}\text { Lag } \\
\text { Length }\end{array}$ \\
\hline GDP & Model C & $1984 / 1998$ & $-5.11^{* *}$ & 2 & $1981 / 1990$ & $-6.27^{*}$ & 0.98 & 0 \\
K & Model C & $1976 / 1985$ & $-5.86^{*}$ & 2 & $1980 / 1984$ & $-4.23^{*}$ & 0.71 & 0 \\
L & Model C & $1977 / 1995$ & -4.33 & 0 & $1980 / 1993$ & $-8.80^{*}$ & 0.63 & 0 \\
EC & Model C & $1979 / 1988$ & $-5.97^{*}$ & 4 & $1980 / 2000$ & $-7.37^{*}$ & 0.97 & 0 \\
ECR & Model C & $1978 / 1996$ & $-6.00^{*}$ & 3 & $1978 / 1994$ & $-7.26^{*}$ & 0.79 & 1 \\
ECTR & Model C & $1978 / 1987$ & $-5.64^{* *}$ & 4 & $1969 / 1982$ & $-4.95^{*}$ & 0.58 & 0 \\
ECI & Model C & $1979 / 2001$ & $-6.17^{*}$ & 2 & $1982 / 990$ & $-7.20^{*}$ & 0.86 & 0 \\
ECA & Model C & $1977 / 2002$ & -4.82 & 3 & $1981 / 1985$ & $-4.26^{* *}$ & 0.97 & 1 \\
First differences & & & & & & & \\
$\Delta$ GDP & Model A & $1982 / 1996$ & $-6.85^{*}$ & 0 & & & & \\
$\Delta$ K & Model A & $1982 / 1987$ & $-7.32^{*}$ & 0 & & & & \\
$\Delta$ L & Model A & $1980 / 1997$ & $-5.21^{*}$ & 0 & & & & \\
$\Delta$ EC & Model A & $1981 / 1989$ & $-8.10^{*}$ & 0 & & & & \\
$\Delta$ ECR & Model A & $1987 / 1992$ & $-8.03^{*}$ & 0 & & & & \\
$\Delta$ ECTR & Model A & $1982 / 1986$ & $-5.79^{*}$ & 0 & & & & \\
$\Delta$ ECI & Model A & $1995 / 2010$ & $-9.92^{*}$ & 0 & & & & \\
$\Delta$ ECA & Model A & $1980 / 2002$ & $-5.91^{*}$ & 0 & & & & \\
\hline
\end{tabular}

Notes: ${ }^{*},{ }^{* *}$, and ${ }^{* * *}$ denote the rejection of the null hypothesis at the $1 \%, 5 \%$, and $10 \%$ levels, respectively. The abbreviations are: real output (GDP), energy consumption (EC), labor (L), capital (K), and the disaggregation of energy consumption into transport sector (ECTR), industrial sector (ECI), residential sector (ECR), and agriculture sector (ECA). The critical values for the LM and RALS-LM tests are obtained from [34,41], respectively.

The results of the unit root tests are not conclusive, so the co-integration test proposed by [35], in which a different order of integration of the variables is allowed, is conducted. Tables 4 and 5 show the results for the ARDL models and their diagnostic tests, such as autocorrelation, heteroscedasticity, normality and Ramsey's RESET. Dummy variables are included to improve the specification of the models (the dummy variables take values of 1 for the year indicated and 0 otherwise: D73 (1973), D823 (1982 and 1983), D83 (1983), D86 (1986), D90 (1990), D95 (1995), D01 (2001), and D09 (2009)). According to the results, at the aggregated level (see Table 4), the cointegration test shows evidence of three long-term relationships between GDP, K, L, and EC at the 5\% significance level or better, when GDP, EC, and L are dependent variables.

Table 4. ADRL co-integration analysis at the aggregated level.

\begin{tabular}{cc}
\hline ADRL Model & F-Test \\
\hline F(GDP I K, L, EC, D86, D95, D09) & $6.34^{* *}$ \\
F(K I GDP, L, EC, D823, D86, D95) & 3.14 \\
F(L I GDP, K, EC, D95, D09) & $7.69^{*}$ \\
F(EC I GDP, K, L, D823, D86, D09) & $10.67^{*}$ \\
\hline
\end{tabular}

Notes: ***, and *** denote the rejection of the null hypothesis at the $1 \%, 5 \%$, and $10 \%$ levels, respectively The abbreviations are: real output (GDP), energy consumption (EC), labor (L), and capital (K). The critical values $(\mathrm{CV})$ for the lower $\mathrm{I}(0)$ and upper $\mathrm{I}(1)$ bounds are taken from [44].

Table 5. ADRL co-integration analysis at the disaggregated level.

\begin{tabular}{cc}
\hline ADRL Model & F-Test \\
\hline F(GDP | K, L, ECTR, D86, D95, D09) & $6.16^{* *}$ \\
\hline F(ECTR | K, L, GDP, D823, D95, D09) & $4.10^{* * *}$ \\
F(GDP | K, L, ECI, D95) & $5.73^{* *}$ \\
F(ECI I K, L, GDP, D86, D09, D01) & $5.61^{* *}$ \\
F(GDP | K, L, ECR, D95) & 3.39 \\
F(ECR | K, L, GDP, D90) & $5.96^{* *}$ \\
\hline F(GDP | K, L, ECA, D95) & $4.49^{* *}$ \\
\hline F(ECA | K, L, GDP, D73, D83, D09) & $8.32^{*}$
\end{tabular}

Notes: $* * *$, and $* * *$ denote rejection of the null hypothesis at the $1 \%, 5 \%$, and $10 \%$ levels, respectively. The abbreviations are: real output (GDP), labor (L), capital (K), and the disaggregation of energy consumption into transport sector (ECTR), industrial sector (ECI), residential sector (ECR), and agriculture sector (ECA). The critical values $(\mathrm{CV})$ for the lower $\mathrm{I}(0)$ and upper $\mathrm{I}(1)$ bounds are taken from [44]. 
At the disaggregated level, the F-test shows evidence of long-run relationships between GDP, L, $\mathrm{K}$ and three consumption sectors when GDP is taken as the dependent variable: in this case at the 5\% significance level when ECTR, ECI and ECA are included as explanatory variables. When the dependent variables are energy consumption by sector, the results show that there is a co-integration relationship in all cases.

Reference [47] points out that, if the variables are co-integrated, there must be a causal link in at least one direction; thus, a vector error correction model (VECM) must be estimated instead of a VAR for Granger causality testing, since the latter would be misspecified, which could lead to incorrect conclusions regarding causality. Table 6 shows the results of causality testing in the short run and long run at the aggregated level.

Table 6. Granger causality test results: Aggregated level.

\begin{tabular}{ccccc}
\hline Explanatory Variables & $\Delta$ GDP & Dependent Variables $\Delta \mathbf{K}$ & $\Delta \mathbf{L}$ & $\Delta$ EC \\
\hline$\Delta \mathrm{GDP}$ & - & $5.33^{* *}$ & $3.02^{* * *}$ & 1.20 \\
\hline$\Delta \mathrm{K}$ & $7.46^{*}$ & - & 1.53 & 1.39 \\
\hline$\Delta \mathrm{L}$ & 1.03 & 2.34 & - & $4.34^{* *}$ \\
\hline$\Delta \mathrm{EC}$ & 1.88 & 2.26 & $7.43^{*}$ & - \\
\hline ECT-1 & $-0.60^{* *}$ & 0.07 & -0.03 & 0.22 \\
Dummy & $\mathrm{D} 83, \mathrm{D} 95, \mathrm{D} 09$ & $\mathrm{D} 823, \mathrm{D} 86, \mathrm{D} 95$ & $\mathrm{D} 83, \mathrm{D} 09$ & $\mathrm{D} 83, \mathrm{D} 09$ \\
\hline Diag. tests & - & - & - & - \\
JB Normal & 2.43 & 2.83 & 3.24 & 2.04 \\
LM test & 2.07 & 1.72 & 0.56 & 0.39 \\
White test & 8.23 & 3.53 & 9.44 & 6.33 \\
Ramsey test & 0.44 & 0.15 & 1.83 & 1.00 \\
\hline
\end{tabular}

Note: ${ }^{* * *}$, and ${ }^{* * *}$ denote significance at the $1 \%, 5 \%$, and $10 \%$ levels, respectively. ECT-1 denotes the estimated coefficient of the lagged error correction term. The abbreviations are: real output (GDP), energy consumption (EC), labor (L), and capital (K).

In the long run, there is evidence of a causal relationship from EC, $\mathrm{K}$, and L to GDP, since the coefficient of ECT-1 is negative and significant at the 5\% level. These results support the growth hypothesis, which suggests that energy is an important factor for economic activity. A reduction in energy consumption, capital, or employment will adversely affect output growth. In terms of implications for energy conservation policies without affecting economic growth, it is important to explore policies related to reducing the intensity of energy and promoting cleaner energy consumption and production. In the short run, there is evidence of causality from K to GDP, which means that capital contains important information to help predict GDP. There is also a causal link from GDP to K and $\mathrm{L}$ at the $5 \%$ and $10 \%$ significance levels, respectively. Finally, there is evidence of a bidirectional causality relationship between $\mathrm{L}$ and $\mathrm{EC}$.

At the disaggregated level, Table 7 show evidence of a causal link in the long run from energy consumption in three sectors (ECTR, ECI, and ECR), K, and L to GDP. This result coincides with the results of the analysis at the aggregated level and implies that a reduction in energy consumption in any of the three sectors, in capital, or in employment will adversely affect output growth. Energy consumption by transport, industry, and the residential sector is a major factor for economic activity in Mexico. In 2011, the final energy consumption across sectors was $48 \%$ for transportation (mainly gasoline and diesel); $29 \%$ for industry; $20 \%$ for residential, commercial, and public; and 3\% for agriculture [29]. 
Table 7. Granger causality test results: Disaggregated level.

\begin{tabular}{ccccccccc}
\hline $\begin{array}{c}\text { Explanatory } \\
\text { Variables }\end{array}$ & $\Delta$ GDP & $\Delta$ ECTR & $\Delta$ GDP & $\begin{array}{c}\text { Dependent } \\
\text { Variables } \Delta \text { ECI }\end{array}$ & $\Delta$ GDP & $\Delta$ ECR & $\Delta$ GDP & $\Delta$ ECA \\
\hline$\Delta \mathrm{GDP}$ & - & 0.46 & - & $2.51^{* * *}$ & - & $3.30^{* * *}$ & - & 1.99 \\
\hline$\Delta \mathrm{K}$ & $6.28^{*}$ & 0.29 & $9.61^{*}$ & 1.11 & $13.34^{*}$ & 1.44 & $2.81^{* * *}$ & 1.83 \\
\hline$\Delta \mathrm{L}$ & 0.47 & 0.22 & 0.000 & 0.62 & 0.00 & $7.40^{*}$ & 0.96 & 0.04 \\
\hline$\Delta \mathrm{ECTR}$ & 0.86 & - & - & - & - & - & - & - \\
$\Delta \mathrm{ECI}$ & - & - & 2.75 & - & - & - & - & - \\
\hline$\Delta \mathrm{ECR}$ & - & - & - & - & 1.39 & - & - & - \\
$\Delta \mathrm{ECA}$ & - & - & - & - & - & - & 1.39 & - \\
ECT-1 & $-0.66^{* *}$ & 0.39 & $-0.82 * *$ & 0.77 & $0.66^{* *}$ & 0.06 & -0.21 & 0.38 \\
Dummy & $\mathrm{D} 95, \mathrm{D} 09$ & $\mathrm{D} 823, \mathrm{D} 09$ & $\mathrm{D} 83, \mathrm{D} 95$ & $\mathrm{D} 01, \mathrm{D} 09$ & $\mathrm{D} 83, \mathrm{D} 95$ & $\mathrm{D} 83, \mathrm{D} 90$ & $\mathrm{D} 83, \mathrm{D} 95, \mathrm{D} 09$ & $\mathrm{D} 83$ \\
\hline Diag. Tests & - & - & - & - & - & - & - & - \\
JB Normal & 1.72 & 1.79 & 2.06 & 1.86 & 1.42 & 1.54 & 1.25 & 0.16 \\
LM test & 5.07 & 2.28 & 1.84 & 4.20 & 1.13 & 1.03 & 3.89 & 0.84 \\
White test & 20.48 & 3.78 & 3.81 & 5.85 & 4.10 & 9.81 & 8.50 & 3.56 \\
Ramsey test & 0.15 & 0.76 & 0.13 & 0.07 & 0.03 & 1.13 & 0.47 & 0.07 \\
\hline
\end{tabular}

Notes: ${ }^{* * *}$, and ${ }^{* * *}$ denote significance at the $1 \%, 5 \%$, and $10 \%$ levels, respectively. ECT-1 denotes the estimated coefficient of the lagged error correction term. The abbreviations are: real output (GDP), labor (L), capital (K), and the disaggregation of energy consumption into transport sector (ECTR), industrial sector (ECI), residential sector $(\mathrm{ECR})$, and agriculture sector (ECA).

In the short run, there is evidence of causality from GDP to ECI and ECR at the $10 \%$ significance level. By contrast, in the short term, there is no evidence of a causal relationship from energy consumption per sector to GDP.

To check the robustness of the results, the alternative methodology proposed by [46] is also applied. Table A2 in Appendix A shows that there is a causal relationship from EC and K to GDP at the $1 \%$ and $10 \%$ significance levels, respectively. There is also a causal relationship from GDP and $\mathrm{L}$ to $\mathrm{K}$ at the $1 \%$ and $10 \%$ significance levels, respectively, and from GDP, EC, and $\mathrm{K}$ to $\mathrm{L}$ at the $1 \%$ significance level. Finally, there is a causal link at the 5\% significance level from L to EC. These results also support the growth hypothesis and confirm the results at the aggregated level.

A causality test between GDP and energy consumption per sector is also performed. The results are shown in Appendix A with Table A3, where the evidence suggests a causal link from GDP to ECR and ECI at the 5\% and 1\% significance levels, respectively. In the short run, these results confirm the evidence shown in Table 7 . Therefore, the dynamics of economic activity contain important information for consumption by the ECR and ECI.

These results also confirm a causal link from energy consumption to economic growth at the aggregated level. This means that energy consumption contains useful information that can help to predict economic growth and that energy conservation policies impact economic activity.

The [36] nonlinear causality test is applied to the residual series of the VECM, estimated for both aggregated and disaggregated energy consumption. The results show no evidence of nonlinear causality from K, L, and GDP to EC, nor do they show evidence of nonlinear causality from K, L, and EC to GDP, when aggregated energy consumption is considered. However, for the disaggregated energy consumption, evidence of a unique nonlinear causality is found running from ECTR, $K$, and $\mathrm{L}$ to GDP (the values $m=L x=L y=1$ and $e=1.5$ are considered for all residual series. The value $e=0.5$ has also been considered, but no evidence of causality has been found. The results of the tests are available from the authors upon request) which means that the past values of ECTR, K, and L help to predict GDP through a more complex means than the linear causality. This relation is not found for the energy consumption of the rest of the sectors.

To summarize, our results are robust to the different methodologies and support the growth hypothesis. The results differ from those in [30-33] for Mexico, which could be due to the different methodologies and the variables employed. However, results are in line with [8] for Mexico. 
Finally, $[3,8,10,11,17]$ also support the growth hypothesis for other countries such as Algeria, China, Philippines and South Africa.

\section{Conclusions and Policy Implications}

This research studies the dynamic relationships between GDP, capital, labor, and energy in Mexico from 1965 to 2014, incorporating structural breaks. Total energy consumption is disaggregated to analyze the dynamics of the different sectors. The results show that most series are stationary in levels with two structural breaks and a deterministic trend. Co-integration testing shows three long-term relationships between GDP, K, L, and EC, whereas at a disaggregated level, there is evidence of long-run relationships between GDP, K, and L and energy consumption in three sectors: ECTR, ECI, and ECA.

In the long run, there is evidence of causality from $\mathrm{EC}, \mathrm{K}$, and L to GDP at both the aggregated and disaggregated (ECTR, ECR, and ECI) levels. This implies that a reduction in energy consumption in any of the three sectors or in total energy consumption, capital, or employment would negatively affect the growth of economic activity. In the case of energy consumption in the transport sector, there is also a nonlinear causal relationship from ECTR, K, and L to GDP. The alternative methodology of [46] confirms the results at the aggregated level, since there is evidence of a causal link from EC to GDP.

These empirical results support the growth hypothesis; a decrease in energy consumption could restrict economic growth in Mexico. This result does not necessarily mean that the ultimate goal of the economic policies should not be to encourage energy consumption as such. For instance, the energy reform program approved on 20 December 2013, and the first package of secondary legislation published on 11 August 2014, focus on the participation of non-renewable resources in the energy sector of Mexico, neglecting their environmental impact. Two thirds of total emissions come from the energy sector. Thus, this policy would be in line with our results but it is in clear contradiction to the environmental goal of reducing greenhouse gas emissions by $30 \%$ by 2020 compared to the baseline. Therefore, Mexico must explore policies related to the most efficient use of energy which allows consuming less energy to produce the same level of product, as well as the production of cleaner energies such as those that are renewables. This is a very important issue in a global context where energy consumption is increasing and the fossil fuel reserves are becoming exhausted.

Acknowledgments: We are grateful to three anonymous reviewers for valuable comments and suggestions that helped to improve the paper. This work was supported under research grant ECO2015-64467-R (MINECO/FEDER), from Dpto. de Educación, Universidades e Investigación del Gobierno Vasco under research grant IT-783-13 and from the National Council for Science and Technology (Consejo Nacional de Ciencia y Tecnología, CONACYT) in Mexico, which is gratefully acknowledged (N265826-2016).

Author Contributions: Mario Gómez, Aitor Ciarreta and Ainhoa Zarraga conceived and designed the experiments; Mario Gómez, Aitor Ciarreta and Ainhoa Zarraga performed the experiments; Mario Gómez, Aitor Ciarreta and Ainhoa Zarraga analyzed the data; Mario Gómez, Aitor Ciarreta and Ainhoa Zarraga contributed analysis tools; Mario Gómez, Aitor Ciarreta and Ainhoa Zarraga wrote the paper.

Conflicts of Interest: The authors declare no conflict of interest. 


\section{Appendix A}

Table A1. Unit root tests without structural breaks.

\begin{tabular}{cccc}
\hline Variable & Deterministic Parameters & ADF Test & PP Test \\
\hline GDP & CT & -2.255 & -2.112 \\
K & CT & -2.826 & -2.900 \\
L & CT & -0.242 & -0.101 \\
EC & CT & -1.706 & -1.694 \\
ECR & CT & 0.238 & 0.318 \\
ECTR & CT & -1.946 & -1.768 \\
ECI & CT & -2.348 & -2.440 \\
ECA & CT & -1.755 & -1.962 \\
First & - & - & - \\
differences & - & - & - \\
$\Delta$ GDP & $\mathrm{C}$ & $-5.054^{*}$ & $-5.054 *$ \\
$\Delta \mathrm{K}$ & $\mathrm{C}$ & $-6.139 *$ & $-6.188^{*}$ \\
$\Delta \mathrm{L}$ & $\mathrm{C}$ & $-6.049^{*}$ & $-6.210^{*}$ \\
$\Delta \mathrm{EC}$ & $\mathrm{C}$ & $-4.908^{*}$ & $-5.013^{*}$ \\
$\Delta \mathrm{ECR}$ & $\mathrm{C}$ & $-5.963^{*}$ & $-6.160^{*}$ \\
$\Delta \mathrm{ECTR}$ & $\mathrm{C}$ & $-4.084^{*}$ & $-4.062 *$ \\
$\Delta \mathrm{ECI}$ & $\mathrm{C}$ & $-8.191 *$ & $-8.066^{*}$ \\
$\Delta \mathrm{ECA}$ & $\mathrm{C}$ & $-5.252^{*}$ & $-5.249^{*}$ \\
\hline
\end{tabular}

Notes: * denotes the rejection of the null hypothesis at the $1 \%$ level. $\mathrm{C}$ denotes constant and CT denotes constant and trend. ADF: Augmented Dickey-Fuller; PP: Phillips-Perron.

Table A2. Toda and Yamamoto causality test results: Aggregated level.

\begin{tabular}{cccc}
\hline From & To & Statistic & Dummy Variables \\
\hline K & GDP & $2.84^{* * *}$ & D83, D95, D09 \\
L & GDP & 0.15 & D83, D95, D09 \\
EC & GDP & $4.61^{*}$ & D83, D95, D09 \\
GDP & K & $9.32^{*}$ & D823, D86, D95 \\
L & K & $2.99^{* * *}$ & D823, D86, D95 \\
EC & K & 1.46 & D823, D86, D95 \\
GDP & L & $6.52^{*}$ & D83, D09 \\
K & L & $5.55^{*}$ & D83, D09 \\
EC & L & $15.42^{*}$ & D83, D09 \\
GDP & EC & 0.35 & D83, D09 \\
K & EC & 0.91 & D83, D09 \\
L & EC & $4.56 * *$ & D83, D09 \\
\hline
\end{tabular}

Note: ${ }^{*}{ }^{* *}$ and ${ }^{* * *}$ denote significance at the $1 \%, 5 \%$ and $10 \%$ levels, respectively.

Table A3. Toda and Yamamoto causality test results: Disaggregated level.

\begin{tabular}{cccc}
\hline From & To & Statistic & Control Variables \\
\hline ECTR & GDP & 1.32 & K, L,D95, D09 \\
GDP & ECTR & 0.33 & K, L, D823, D09 \\
ECR & GDP & 1.13 & K, L, D83, D95 \\
GDP & ECR & $3.73^{* *}$ & K, L,D83, D90 \\
ECI & GDP & 0.52 & K, L, D83, D95 \\
GDP & ECI & $5.32^{*}$ & K, L, D09, D2001 \\
ECA & GDP & 1.32 & K, L, D83, D95, D09 \\
GDP & ECA & 0.87 & K, L, D83
\end{tabular}

Note: ${ }^{*}$ and ${ }^{* *}$ denote rejection of the null hypothesis at the $1 \%$ and $5 \%$ levels, respectively. 


\section{References}

1. Kraft, J.; Kraft, A. On the relationship between energy GNP. J. Energy Dev. 1978, 3, 401-403.

2. Payne, J. A survey of the electricity consumption-growth literature. Appl. Energy 2010, 87, 723-731. [CrossRef]

3. Bélaïd, F.; Abderrahmani, F. Electricity consumption and economic growth in Algeria: A multivariate causality analysis in the presence of structural change. Energy Policy 2013, 55, 286-295. [CrossRef]

4. International Energy Agency (IEA). Energy and Air Pollution. World Energy Outlook Special Report. 2016. Available online: https:/ / www.iea.org/ (accessed on 5 October 2016).

5. Apergis, N.; Payne, J.E. A dynamic panel study of economic development and electricity consumption-growth nexus. Energy Econ. 2011, 33, 770-781. [CrossRef]

6. Ciarreta, A.; Zarraga, A. Electricity consumption and economic growth in Spain. Appl. Econ. Lett. 2010, 17, 1417-1421. [CrossRef]

7. Costantini, V.; Martini, C. The causality between energy consumption and economic growth: A multi-sectoral analysis using non-stationary cointegrated panel data. Energy Econ. 2010, 32, 591-603. [CrossRef]

8. Destek, M.A.; Aslan, A. Renewable and non-renewable energy consumption and economic growth in emerging economies: Evidence from bootstrap panel causality. Renew. Energy 2017, 111, 757-763. [CrossRef]

9. Eggoh, J.C.; Bangake, C.; Rault, C. Energy consumption and economic growth revisited in African countries. Energy Policy 2011, 39, 7408-7421. [CrossRef]

10. Kumar, R.R.; Stauvermann, P.J.; Loganathan, N.; Kumar, R.D. Exploring the role of energy, trade and financial development in exploring economic growth in South Africa: A revisit. Renew. Sustain. Energy Rev. 2015, 52, 1300-1311. [CrossRef]

11. Lee, C.C.; Chang, C.P. Structural breaks energy consumption, and economic growth revisited: Evidence from Taiwan. Energy Econ. 2005, 27, 857-872. [CrossRef]

12. Mirza, F.M.; Kanwal, A. Energy consumption, carbon emissions and economic growth in Pakistan: Dynamic causality analysis. Renew. Sustain. Energy Rev. 2017, 72, 1233-1240. [CrossRef]

13. Ozturk, I.; Acaravci, A. The long-run and causal analysis of energy, growth, openness and financial development on carbon emissions in Turkey. Energy Econ. 2013, 36, 262-267. [CrossRef]

14. Rafindadi, A.A. Does the need for economic growth influence energy consumption and $\mathrm{CO}_{2}$ emissions in Nigeria? Evidence from the innovation accounting test. Renew. Sustain. Energy Rev. 2016, 62, 1209-1225. [CrossRef]

15. Rafindadi, A.A.; Ozturk, I. Effects of financial development, economic growth and trade on electricity consumption: Evidence from post-Fukushina Japan. Renew. Sustain. Energy Rev. 2016, 54, 1073-1084. [CrossRef]

16. Tang, C.F.; Shahbaz, M.; Arouri, M. Re-investigating the electricity consumption and economic growth nexus in Portugal. Energy Policy 2013, 62, 1515-1521. [CrossRef]

17. Wolde-Rufael, Y. Electricity consumption and economic growth in transition countries: A revisit using bootstrap panel Granger causality analysis. Energy Econ. 2014, 44, 325-330. [CrossRef]

18. Lean, H.H.; Smyth, R. Disaggregated energy demand by fuel type and economic growth in Malaysia. Appl. Energy 2014, 132, 168-177. [CrossRef]

19. Liddle, B.; Lung, S. Revisiting energy consumption and GDP causality: Importance of a priori hypothesis testing, disaggregated data and heterogeneous panels. Appl. Energy 2015, 142, 44-55. [CrossRef]

20. Rahman, M.d.S.; Noman, A.H.M.d.; Shahari, F. Does economic growth in Malaysia depend on disaggregate energy? Renew. Sustain. Energy Rev. 2017, 78, 640-647. [CrossRef]

21. Tsani, S. Energy consumption and economic growth: A causality analysis for Greece. Energy Econ. 2010, 32, 582-590. [CrossRef]

22. Zhang, W.; Yang, S. The influence of energy consumption of China on its real GDP from aggregated and disaggregated viewpoints. Energy Policy 2013, 57, 76-81. [CrossRef]

23. Pablo-Romero, M.P.; Sánchez-Braza, A. Productive energy use and economic growth: Energy, physical and human capital relationships. Energy Econ. 2015, 49, 420-429. [CrossRef]

24. Ayres, R.; Voudouris, V. The economic growth enigma: Capital, labour and useful energy? Energy Policy 2014, 64, 16-28. [CrossRef]

25. Shen, K.; Whalley, J. Capital-labor-energy substitution in nested CES production functions for China. In The Economies of China and India Cooperation and Conflict; World Scientific: Singapore, 2017; Volume 2, pp. 15-27. 
26. Pablo-Romero, M.P.; Cruz, L.; Barata, E. Testing the transport energy-environmental Kuznets curve hypothesis in the EU27 countries. Energy Econ. 2017, 62, 257-269. [CrossRef]

27. Chai, J.; Lu, Q.-Y.; Wang, S.-Y.; Lai, K.K. Analysis of road transportation energy consumption demand in China. Transp. Res. Part D 2016, 48, 112-124. [CrossRef]

28. Chiou-Wei, S.Z.; Chen, C.-F.; Zhu, Z. Economic growth and energy consumption revisited-Evidence from linear and nonlinear Granger causality. Energy Econ. 2008, 30, 3063-3076. [CrossRef]

29. Secretary of Energy. Estrategia Nacional de Energía 2013-2027. 2015. Available online: http:/ / www.energia. gob.mx/res/PE_y_DT/pub/2013/ENE_2013-2027 (accessed on 13 March 2015).

30. Cheng, B.S. Energy Consumption and Economic Growth in Brazil, Mexico and Venezuela: A Time Series Analysis. Appl. Econ. Lett. 1997, 4, 671-674. [CrossRef]

31. Galindo, L.M.; Sánchez, L. El consumo de energía y la economía mexicana: Un análisis empírico con VAR. Econ. Mex. Nueva Época 2005, 0, 271-298.

32. Bozoklu, S.; Yilanci, V. Energy consumption and economic growth for selected OECD countries: Further evidence from the Granger causality test in the frecuency domain. Energy Policy 2013, 63, 877-881. [CrossRef]

33. Yıldırım, E.; Sukruoglu, D.; Aslan, A. Energy consumption and economic growth in the next 11 countries: The boostrapped autoregressive metric causality approach. Energy Econ. 2014, 44, 14-21. [CrossRef]

34. Meng, M.; Lee, L.; Payne, J.E. RALS-LM unit root test with trend breaks and non-normal errors: Application to the Prebisch-Singer hypothesis. Stud. Nonlinear Dyn. Econ. 2017, 21, 31-45. [CrossRef]

35. Pesaran, M.H.; Shin, Y.; Smith, R. Bounds testing approaches to the analysis of level relationships. J. Appl. Econ. 2001, 16, 289-326. [CrossRef]

36. Bai, Z.; Wong, W.K.; Zhang, B. Multivariate linear and nonlinear causality tests. Math. Comput. Simul. 2010, 81, 5-17. [CrossRef]

37. Stern, D.I. A multivariate cointegration analysis of the role of energy in the US macroeconomy. Energy Econ. 2000, 22, 267-283. [CrossRef]

38. Dickey, D.A.; Fuller, W.A. Likelihood Ratio Tests for Autoregressive Time Series with a Unit Root. Econometrica 1981, 49, 1057-1072. [CrossRef]

39. Phillips, P.C.B.; Perron, P. Testing for a Unit Roots in a Time Series Regression. Biometrika 1988, 75, 335-346. [CrossRef]

40. Lee, J.; Strazicich, M. Minimum Lagrange Multiplier unit root test with two structural breaks. Rev. Econ. Stat. 2003, 85, 1082-1089. Available online: http:/ / www.jstor.org/stable/3211829 (accessed on 25 January 2015). [CrossRef]

41. Lee, J.; Strazicich, M. Minimum LM Unit Root Test with One Structural Breaks; Manuscript; Department of Economics, Appalachian State University: Boone, NC, USA, 2004; pp. 1-16.

42. Lee, J.; Strazicich, M.; Meng, M. Two-step LM unit root tests with trend-breaks. J. Stat. Econ. Methods 2012, 1, 81-107. Available online: http:/ / www.scienpress.com/Upload/JSEM/Vol\%201_2_8.pdf (accessed on 25 January 2015).

43. Payne, J.; Vizek, M.; Lee, J. Stochastic convergence in per capita fossil consumption in U.S. states. Energy Econ. 2017, 62, 382-395. [CrossRef]

44. Narayan, P.K. The saving and investment nexus for China: Evidence from cointegration test. Appl. Econ. 2005, 37, 1979-1990. [CrossRef]

45. Granger, C.W.J. Investigating causal relations by econometrics models and cross spectral methods. Econometrica 1969, 37, 424-438. [CrossRef]

46. Toda, H.Y.; Yamamoto, T. Statistical inference in vector autoregressions with possibly integrated processes. J. Econ. 1995, 66, 225-250. [CrossRef]

47. Granger, C.W.J. Some recent development in a concept of causality. J. Econ. 1988, 39, 199-211. [CrossRef]

48. Hiemstra, C.; Jones, J.D. Testing for linear and nonlinear Granger causality in the stock price-volume relation. J. Financ. 1994, 49, 1639-1664. [CrossRef]

49. World Bank. Available online: http:/ / databank.bancomundial.org/data (accessed on 13 March 2016).

50. Sadorsky, P. Trade and energy consumption in the Middle East. Energy Econ. 2011, 33, 739-749. [CrossRef]

51. Wolde-Rufael, Y. Energy consumption and economic growth: The experience of African countries revisited. Energy Econ. 2009, 31, 217-224. [CrossRef] 
52. The Conference Board Total Economy Database. Available online: http://www.conference-board.org/data / economydatabase/ (accessed on 13 March 2015).

53. Ruiz, P. Evolución y Determinantes del Tipo de Cambio en México; Documento de Trabajo, Universidad Nacional Autónoma de México: Ciudad de México, México, 1997; pp. 1-39. 